\title{
Forecasting of Unemployment and Economic Growth for Turkey: ARIMA Model Application
}

\author{
U. Ayik ${ }^{1 *}$, G. Erkal $^{2}$ \\ ${ }^{1}$ Atatürk University, Social Sciences Institute, Department of Econometrics, Erzurum, Turkey \\ 2 Atatürk University, Faculty of Economics and Administrative Sciences, Department of Econometrics, Erzurum, Turkey
}

\section{A R T I C L E I N F O}

\begin{tabular}{lccc}
\hline Article history: & & & \\
Received & 16 & April & 2021 \\
Revision & 03 & June & 2021 \\
Accepted & 07 & June & 2021 \\
Available Online & 29 & August & 2021
\end{tabular}

\section{Keywords:}

Unemployment rate

Economic growth

ARIMA model

Ex-Post forecasting

Ex-Ante forecasting

\begin{abstract}
A B S T R A $\mathrm{C}$
The main purpose of the study is to obtain the forecasting values of unemployment rate and economic growth in the coming years. Since unemployment and economic growth series are not stationary series in level $\mathrm{I}(0)$, the preferred model for forecasting is the Autoregressive Integrated Moving Average (ARIMA) model. Models determined for unemployment and economic growth forecasting with the help of model measurement criteria are ARIMA $(2,1,1)$ and ARIMA $(1,1,0)$ models respectively. In the study, the period between 1988-2017 has been considered as the prediction period and the forecasting values obtained for this period have been compared graphically with the actual values and the success of the forecasting has been evaluated. Since the forecasting power of the models is successful, forecasts have been made for the 2018-2019 (ex-post) period and it has been determined that the error rate between forecasting values and actual values is at a level to be considered good. Forecasting values for the 2020-2025 (ex-ante) period have been designed, it has been observed that unemployment rates will increase in a fluctuating manner in the coming years and economic growth is in a constant rising trend.
\end{abstract}

@(๑) Turkish Journal of Forecasting by Giresun University, Forecast Research Laboratory is licensed under a Creative Commons Attribution-ShareAlike 4.0 International License.

\section{Introduction}

Unemployment is a problem for all developed and developing countries from past to present. It negatively affects the living standards of people and the socio-economic status of nations. Just as unemployment affects many macroeconomic variables, there are many factors affecting unemployment and economic growth is an important factor among these. For this reason, how the change in back the social balance and economic structure of a country will create a course in unemployment rates is an important issue for the economies of the country.

After the 2001 crisis, the Turkish economy entered an important growth trend, but these growth figures have not had the desired effect on important macroeconomic variables such as unemployment, inflation and exchange rates. For this reason, it is important what scenarios the possible growth or contraction in the Turkish economy will create in the unemployment rates, which are shown as one of the most important macroeconomic indicators for the economies of the country. Therefore, what kind of image economic growth and unemployment will present for Turkey in the following years has become an important issue that needs to be researched.

\footnotetext{
* Corresponding author.

E-mail addresses: ugur.ayik@erzurum.edu.tr (Uğur Ayik), gerkal@atauni.edu.tr (Gökhan Erkal)
} 
The aim of this study is to forecast unemployment rates and economic growth rather than to reveal the relationship between unemployment and economic growth. Therefore, the background of this study is to determine with the most appropriate forecasting models what unemployment rates and economic growth in Turkey will look like in the following years.

ARIMA model is one of the most preferred models when generally forecasting unemployment and economic growth in the literature. In this study, ARIMA model is used to forecast unemployment rates and economic growth variables. Various model measurement criteria are used to determine the most appropriate ARIMA models. Before the ARIMA model is implemented, theoretical information is presented about the autoregressive (AR), moving average (MA) and autoregressive moving average (ARMA) processes that make up the structure of the model. After comparing with charts and tables, the actual values with the forecasting values obtained for prediction and ex-post periods using the most appropriate ARIMA models and the forecasting sensitivity of the models have been evaluated and the forecasting values for the ex-ante period have been obtained. In the concluding part of the study, the forecasting results obtained for ex-post and ex-ante periods have been interpreted after evaluation process.

\section{Literature Review}

In previous studies were tried to be predicted unemployment rates and economic growth using different time series and different forecasting models. In this part of the study, featured studies in Turkey and around the world for forecasting of unemployment and economic growth were presented and evaluated in summary.

Ali and Altintas (2015) used the AR model to obtain the forecasting values of the unemployment and inflation series in 2015 and 2016 in the study they used the time series between 2000 and 2014. First, 2015 and 2016 values were forecasted for inflation, then 2015 and 2016 values were forecasted for unemployment. After obtaining forecasting values for variables in 2015 and 2016, a simple regression model was applied to reveal the direction and nature of the relationship between them [1].

Meyer and Tasci (2015) tried to predict unemployment rates in the United States for the period 1976M1-2010M12 using monthly data covering the period 1948M1-1975M12. AR, generalized autoregressive (GAR) and selfstimulated threshold autoregressive (SETAR) models were used to forecast unemployment. GAR and SETAR models were ignored because the AR model performed better [2].

Tasci and Treanor (2015) measured the success of models using unemployment forecasting models while real unemployment rate data in the United States were known during the 2008 crisis. Vector autoregression (VAR) model and FLOW-UC model were used to forecast unemployment rates. As a result, none of the unemployment forecasting models was performed very well during the Great Recession and the recovery period ahead [3].

Karlsson and Javed (2016) aimed to forecast and model the unemployment rates in Sweden. Using quarterly data for the period 1983Q1-2010Q4, multi-variable time series model VAR with single-variable time series models seasonal autoregressive integrated moving average (SARIMA) and SETAR were used to forecast the period 2011Q1 2015Q4. According to the model measurement criteria root mean square error (RMSE), mean absolute error (MAE), mean absolute percent error (MAPE), the SETAR model was found to offer the best forecasting. Causality and cointegration analyses were also carried out in the study [4].

Mahmudah (2017) forecasted unemployment rates in Indonesia for the period 2016-2025 with the ARIMA model, using annual data covering the period 1986-2015. Since the actual unemployment rate series in Indonesia were not stationary at the level, the differentiation process was necessary. ARIMA model was used because it was not convenient to use AR and MA models in non-stationary series. According to the results obtained, ARIMA $(0,2,1)$ model was found to be the most appropriate model in the unemployment forecasting in Indonesia. According to the forecasting results, the unemployment rate in Indonesia was found to be constantly decreasing [5].

Tuzemen and Yildiz (2018) predicted unemployment rates in Turkey with Total and Multiplied-Seasonal HoltWinters methods. In the analysis of the methods, the ex-post forecasting period of January 2015-October 2016 was used for monthly unemployment rates and the ex-ante forecasting period was analyzed with the help of the best forecasting method. Methods were compared according to model measurement criteria mean squared error (MSE), MAPE. It was found that the Total-Seasonal HW method gives a more successful result compared to the other method. Using this method, it was found out that unemployment rates will continue to increase when the ex-ante forecasting period of 11/2016-01/2018 is analyzed for Turkey's unemployment rates [6]. 
Dritsakis and Klazoglou (2018) aimed to achieve the most appropriate unemployment forecasting model for the United States by using SARIMA and the generalized autoregressive conditional heteroskedasticity (GARCH) models. Monthly data covering the period of January 1955-July 2017 were used in the study. The best model obtained using one or more of these models was $\operatorname{SARIMA}(1,1,2)(1,1,1) 12-\operatorname{GARCH}(1,1)$. Model measurement criteria was used when determining this model: RMSE, MAPE and Theil coefficient [7].

Claveria (2019) forecast unemployment rates using the degree of consensus in consumers' expectations in 8 European countries (Austria, Germany, France, Italy, Greece, Portugal, the Netherlands, the United Kingdom). Using monthly data covering the period January 2007-December 2016, he obtained monthly unemployment forecasting values for 2017. He preferred the ARIMA model as the most appropriate model for forecasting unemployment rates [8].

The models applied in previous unemployment prediction studies in the world and Turkey provide the data by which unemployment forecasting models should be taken into account in this study and for the next studies as well. After the selected literature on the forecasting of unemployment rates has been introduced as a summary, the economic growth forecasting literature summary is given.

Wang (2016) tried to achieve economic growth forecasting values between 2015 and 2020 for the city of Shenzhen using economic growth actual data from 1987 to 2014. The ARIMA model was the preferred model to obtain the forecasting values and the ARIMA $(5,3,7)$ model was selected as the most appropriate model. First of all, forecasting values for 1987-2014 were determined and compared with actual values. Due to the good predictive sensitivity, forecasting values were obtained for 2015-2020 and it was determined that the five years of economic growth predicted for the city of Shenzhen showed a slowdown trend [9].

Higgins et al. (2016) tried to achieve economic growth and inflation forecasting values for China for the period 2011M1-2015M1 1 using monthly economic growth and inflation data from 2000M1 to 2010M12. Many forecasting models were used in the study (AR, Benchmark, Random Walk, Standard VAR, Minnesota) and these models were evaluated according to the RMSE model measurement criteria. According to the findings, it was concluded that China's future economic growth will be L-shaped (which means uncertainty about the recovery of the economy) rather than the U-shape (which means stagnation in the economy) [10].

Chuku et al. (2019) investigated the forecasting performance of Artificial Neural Networks and Non-Parametric Regression Models in relation to more standard Box-Jenkins and Structural Economenometric Modeling approaches used to predict economic time series in emerging economies. In the study quarterly data covering the period 1970Q12016Q4 were used. According to the results obtained using different forecasting performance criteria; especially when related commodity prices, trade, inflation and interest rates were used as input variables, it was found that Artificial Neural Networks and Non-Parametric Regression Models perform better than Structural Econometric and ARIMA Models in the prediction of economic growth for selected African border economies (Kenya, Nigeria, South Africa) [11].

Erdogdu (2020) aimed to predict Turkey's GDP growth in the period 2006Q1-2018Q3 with a Mixed Data Sampling (MIDAS) approach using monthly tax revenues. In the study, the aggregated-regression model and alternative MIDAS models were predicted and forecasting values were obtained. Compared to the performance of Turkey's predictive models for GDP growth, the PGM-Almon model was found to offer better results than MIDAS models [12].

Gecgil and Akgul (2020) aimed to predict GDP values for Turkey by using the data between 1998 and 2017. GDP was taken as dependent variable in the study; household consumption expenditure-government final consumption expenditure, import-export, fixed capital investment-total domestic savings, gross foreign debt stock-industryproduction and exchange rates were determined as independent variables and the forecasting values of GDP in 19982017 were tried to be obtained with Artificial Neural Networks technology considering that these independent variables will affect GDP. Since the resulting GDP forecasting values and actual values are very close to each other, it has been decided that the forecasting power of Artificial Neural Networks is high [13].

Jeric et al. (2020) aimed to obtain forecasting values for 2016 of economic development and inflation in Croatia using annual data from 6 different institutions in Croatia for the period 2006-2015. In the study, efficiency and biasedness test following Davies and Lahiri econometric framework based on three-dimensional panel dataset were applied. The forecasting values obtained for 2016 were compared with the forecasting values of the European Commission. As a result of efficiency and biasedness test, it was determined that the forecasting values of economic growth and inflation variables are not satisfactory [14]. 
According to selected literature, AR or ARIMA models have often been preferred for unemployment and economic growth predictions. It has been tried to obtain the most appropriate models by taking advantage of various model measurement criteria. Although there have been numerous studies in the world for unemployment and economic growth predictions, it has been determined that not enough studies have been carried out in Turkey yet. For this reason, with the ARIMA model, which is one of the most preferred models for unemployment and economic growth predictions in the literature, unemployment rates and economic growth in Turkey have been tried to be predicted and the forecasting results obtained have been interpreted and evaluated.

\section{Theoretical Background}

\subsection{ARIMA Model}

The models used in the literature for predictions of unemployment and economic growth are usually AR, MA or ARIMA models. ARIMA is the preferred predictive model when forecasting non-stationary time series. Since the series used in the study are not stationary I(0) at the level, the ARIMA model has been used when forecasting the unemployment rate and GDP series for the prediction period, ex-post and ex-ante periods. Before the theoretical structure and implementation of the ARIMA model, the AR, MA and ARMA processes that constitute this model have been mentioned. When introducing the theories of AR, MA, ARMA and ARIMA models, models of the unemployment rate (Ln『UR】_t) are shown. During the implementation phase of the ARIMA model, besides unemployment rate predictions, prediction results for the GDP variable have also been presented.

\subsubsection{AR process}

Modelling of $L n U R_{t}$ in period $t$,

$$
\left(L n U R_{t}-\delta\right)=\alpha_{1}\left(\operatorname{Ln} U R_{t-1}-\delta\right)+u_{t}
$$

Here $\delta$ is mean of $L n U R$, and $u_{t}$ is an unrelated random error term with zero mean and constant variance $\sigma^{2}$. In this case, it can be said that $L n U R_{t}$ is in line with the first-degree autoregressive or AR(1) process. The value of $L n U R$ in the period $t$ depends on the value it received in the previous period and a random term, and $L n U R$ values are written in the form of deviations from their averages. In other words, this model says that the LnUR predicted value in the period $t$ is nothing more than a ratio of its value in the period $(\mathrm{t}-1)\left(=\alpha_{1}\right)$ plus a random or disrupting effect in the period $\mathrm{t}$, and $L n U R$ values are also written here in the form of deviations from their averages. In general, the $\mathrm{p}$-degree autoregressive or $\mathrm{AR}(\mathrm{p})$ process is as follows:

$$
\left(\operatorname{LnUR}_{t}-\delta\right)=\alpha_{1}\left(\operatorname{LnUR}_{t-1^{-}} \delta\right)+\alpha_{2}\left(\operatorname{LnU} R_{t-2^{-}} \delta\right)+\ldots+\alpha_{p}\left(\operatorname{LnUR} R_{t-p^{-}} \delta\right)+u_{t}
$$

\subsubsection{MA process}

The AR process is not the only mechanism that $L n U R$ can derive from. LnUR can also be modelled as follows:

$$
\operatorname{LnUR}_{t}=\mu+\beta_{0} u_{t}+\beta_{1} u_{t-1}
$$

In model number $3, \mu$ is a constant, and as in models number 1 and $2, \mathrm{u}$ is white noise probable disrupting term. In model number 3, LnUR in the period t is a constant term plus the moving average of current and previous error terms. In this case, it can be said that $L n U R$ is in line with the first-degree moving average or MA(1) process. More generally, the q-degree moving average or MA(q) process can be modeled as follows:

$$
\operatorname{LnUR}_{t}=\mu+\beta_{0} u_{t}+\beta_{1} u_{t-1}+\beta_{2} u_{t-2}+\ldots+\beta_{q} u_{t-q}
$$

The moving average process is a linear combination of white noise error terms.

\subsubsection{ARMA process}

The $L n U R$ series can bear both AR and MA features, so it becomes an ARMA model. Then $L n U R_{t}$ is in line with the ARMA $(1,1)$ process and can be modeled as follows:

$$
\operatorname{LnUR}_{t}=\theta+\alpha_{1} \operatorname{LnUR} R_{t-1}+\beta_{0} u_{t}+\beta_{1} u_{t-1}
$$


The model given above has an autoregressive and a moving average term. $\theta$ refers to constant term. In general terms, the $\operatorname{ARMA}(\mathrm{p}, \mathrm{q})$ process has $\mathrm{p}$ autoregressive and $\mathrm{q}$ moving average terms.

\subsubsection{ARIMA process}

If a difference is taken $d$ times to make a series stationary and the $\operatorname{ARMA}(p, q)$ model is applied to it, it is stated that the initial time series is $\operatorname{ARIMA}(p, d, q)$, that is, the autoregressive integrated moving average time series. Here $p$ is the number of autoregressive terms, $d$ is the number of times the difference must be taken to stabilize the series, and $q$ is the number of moving average terms. For example, for an ARIMA $(2,1,2)$ time series to be stationary, the difference must be taken once $(d=1)$, and this (first difference taken) time series can be modelled as an ARMA $(2,2)$ process, that is, two autoregressive and two moving average terms. If the series is initially stationary, that is, in the case of $d=0, \operatorname{ARIMA}(p, d=0, q)=\operatorname{ARMA}(p, q)$ is in stationary process. If $\mathrm{d}$ and $\mathrm{q}$ are zero, the $\operatorname{ARIMA}(\mathrm{p}, 0,0)$ process means a pure $\operatorname{AR}(\mathrm{p})$ stationary process, and if $d$ and $p$ are zero, the $\operatorname{ARIMA}(0,0, q)$ process means a pure $\operatorname{MA}(\mathrm{q})$ stationary process. As a result, if $p, d$ and $q$ values are available, it will be understood that according to which process the modelling will be made [18].

\subsubsection{Box-Jenkins methodology}

Box-Jenkins Methodology is the most preferred method when analyzing time series. This method discusses whether a time series discussed is stationary and contains seasonal effects. These models are also called the BoxJenkins model because ARMA models are easily analyzed with this method [19]. It is important to note that in order to use the Box-Jenkins method, a time series must either be stationary or become stationary when the difference is taken once or more [18]. Box-Jenkins Methodology is used to obtain the most appropriate ARIMA models.

Box-Jenkins Methodology stages are as follows [17]:

Stage 1: Identification

At this stage, appropriate p, d, q values are determined. For this, the correlogram of the time series is drawn and examined.

Stage 2: Estimation

The ARIMA model determined in the light of the first stage evaluations is predicted.

Stage 3: Diagnostic checking

At this stage, it is investigated whether the predicted ARIMA model is appropriate for analyzed series. For this, correlogram of error terms of the regression is examined.

Stage 4: Forecasting

Forecasting is made with the most appropriate ARIMA model.

\section{Empirical Results}

In the study, the period 1988-2017 and the period 2018-2019 are considered as the prediction period and the expost period respectively. The period 2020-2025 has been designed as the ex-ante period. Forecasting values for the prediction period have been determined with the help of the most appropriate model using actual data covering the period 1988-2017, and actual values and forecasting values for the period in question have graphically been compared. In the light of the information obtained from the charts, the prediction has been made for the period 2018 2019, which has been determined as the ex-post period due to the good predictive power of the models used. The sensitivity of the forecasting has been investigated by comparing forecasting values with actual values. The GDP variable has been used to represent economic growth. The unemployment rate data and GDP data used in the research are annual data obtained from the TURKSTAT database and the World Bank database, respectively $[15,16]$.

Natural logarithms of unemployment rate and GDP variables have been included in the study to protect the series against possible changing variance and partially autocorrelation [17]. Since the unemployment and GDP series are not stationary at the level of I (0), they are made stationary by taking their first difference. By applying the BoxJenkins (1976) methodology, firstly, forecasting values for the prediction period have been obtained with the most appropriate ARIMA models, and then the forecasting values for the ex-post and ex-ante periods have been determined. 
After introducing theoretical framework of the ARIMA model in the theoretical background, the process of determining the most appropriate ARIMA models starts in order to predict the unemployment rate and GDP series in the analysis section.

1- Identification:

In the first stage, first of all, the charts of the level values of the series are given and evaluated. Augmented DickeyFuller (ADF) and Phillips-Perron (PP) unit root tests are then applied to confirm stationarity state of the series.

LNUR

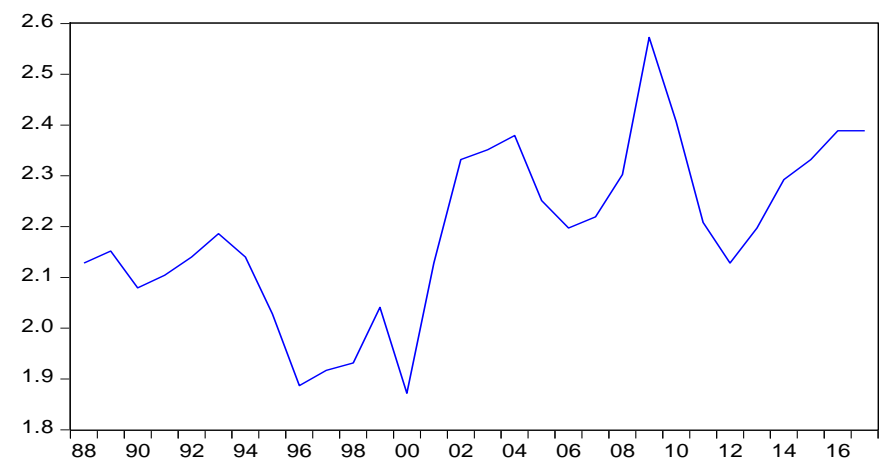

LNGDP

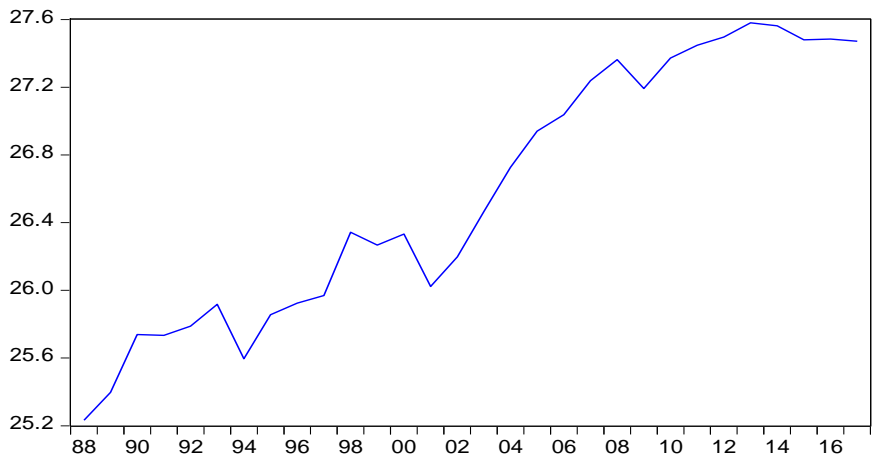

Figure 1. Time series charts for level values of series

In Figure 1, time series charts of level values of the variables used in the models are presented. It can be interpreted that the values of both series over time show deviations from their mean values, that is, they are not stationary. The evaluation of whether series are stationary or not from the charts gained certainty with ADF and PP unit root tests. Descriptive statistics of level values of the series are given in Table 1 and are briefly evaluated before the statistical results of the unit root tests are given.

Table 1. Descriptive statistical information for series

\begin{tabular}{ccc}
\hline & Unemployment Rate $($ LnUR $)$ & GDP $($ LnGDP $)$ \\
\hline Mean & 2.189 & 26.573 \\
\hline Median & 2.192 & 26.404 \\
\hline Maximum & 2.573 & 27.580 \\
\hline Minimum & 1.872 & 25.233 \\
\hline Std. Dev. & 0.168 & 0.767 \\
\hline Skewness & -0.039 & -0.051 \\
\hline Kurtosis & 2.654 & 1.525 \\
\hline Jarque-Bera & 0.158 & 2.732 \\
\hline Probability & 0.924 & 0.255 \\
\hline Observations & 30 & 30 \\
\hline
\end{tabular}

According to Table 1, it has been found out that distributions of series are skewed to the left (minus direction) because skewness coefficients of unemployment and GDP series are less than zero $(\mathrm{SC}<0)$, and their distribution is flatter than normal distribution because kurtosis coefficients of series are less than three $(\mathrm{KC}<3)$. When Jarque-Bera probability values are examined, it has been determined that the basic hypothesis stating that the series are normally distributed could not be rejected, that is, the series show a normal distribution.

Table 2 shows unit root test statistics for the series used in the study. Schwarz information criteria and NeweyWest Bandwidth information criteria are used in ADF and PP unit root tests respectively.

Table 2. Results of ADF and PP unit root tests (Constant)

\begin{tabular}{ccccc}
\hline & \multicolumn{2}{c}{ ADF Unit Root Test Stat. } & \multicolumn{2}{c}{ PP Unit Root Test Stat. } \\
\hline Variable & $t$-statistics & Prob. value & $t$-statistics & Prob. value \\
\hline LnUR & -1.7329 & 0.4048 & -1.6200 & 0.4599 \\
\hline$\Delta$ LnUR & -4.5232 & $0.0013^{*}$ & -6.4683 & $0.0000^{*}$ \\
\hline$L n G D P$ & -1.3597 & 0.5878 & -1.3597 & 0.5878 \\
\hline$\Delta$ LnGDP & -5.7488 & $0.0001^{*}$ & -5.7565 & $0.0000^{*}$ \\
\hline
\end{tabular}

$\Delta$ represents difference processor and $*$ refers to meaningfulness at $1 \%$ importance level. 
Looking at Table 2, where unit root test statistics of series are presented, it is seen that the series that are not stationary at 0.01 significance level become stationary when first differences are taken. After the first differences are taken, time series charts of series that become stationary are presented in Figure 2.

DLNUR

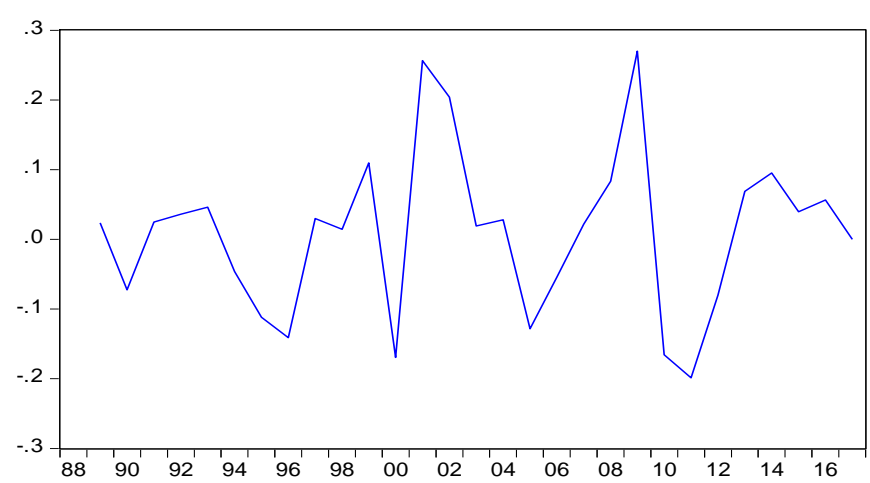

DLNGDP

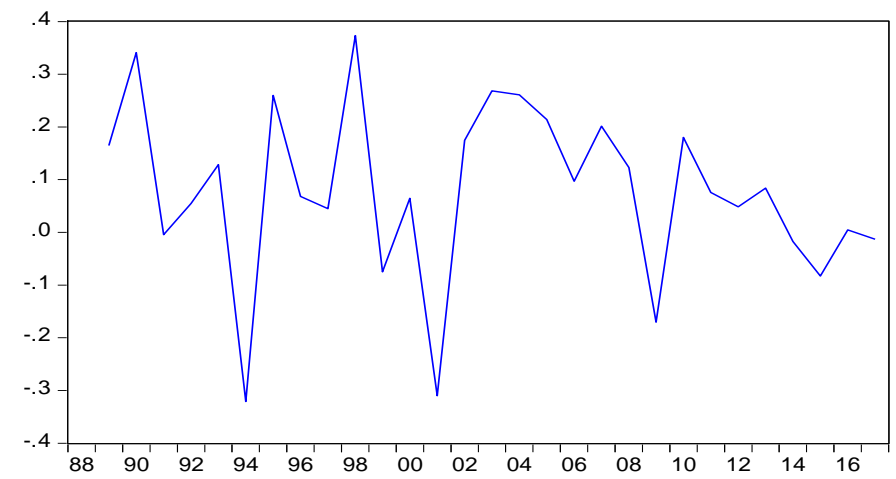

Figure 2. Time series charts for series taken first differences

In Figure 2, it is seen that the series which first differences are taken show a stationary image. After determining stationarity levels of the series, correlograms of the series are examined to predict the ARIMA $(p, d, q)$ model. Correlograms of unemployment rate and GDP series are given in Figure 3 and Figure 4.

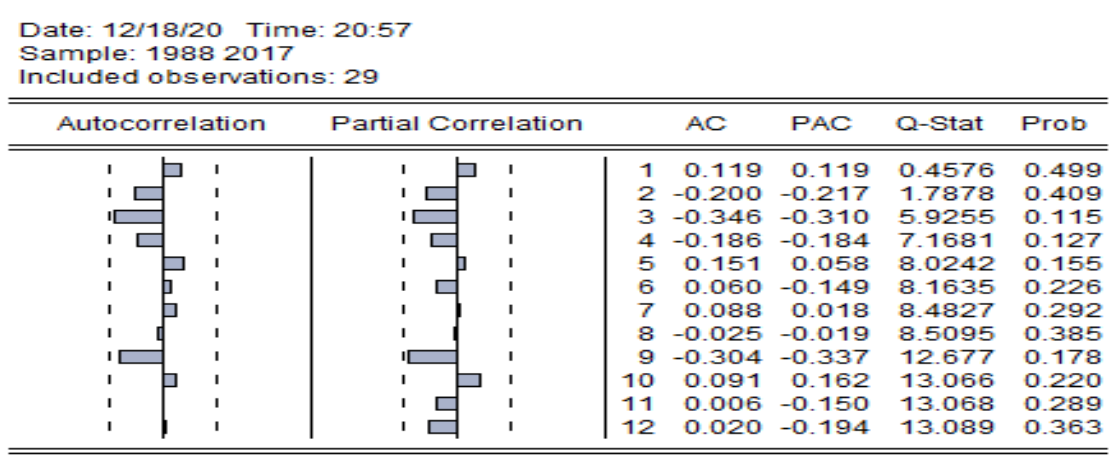

Figure 3. Correlogram of the staticized unemployment series $(d=1)$

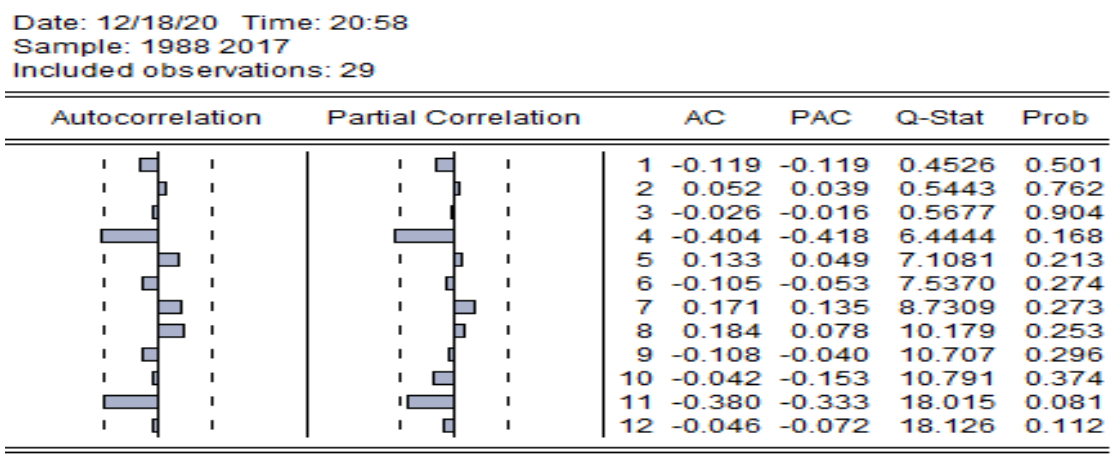

Figure 4. Correlogram of the staticized GDP series $(d=1)$

\section{2- Estimation:}

The estimated ARIMA models determined for $p, d, q$ in the first stage are given below.

Unemployment Model; $\Delta L n U R_{t}=0.010592+0.677028 \Delta L n U R_{t-1}-u_{t-1}$

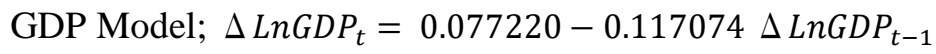

\section{3- Diagnostic Checking:}

Various model measurement criteria are used to build up a good ARIMA models for series. The results of ARIMA models are given in Table 3. 
Table 3. Results of ARIMA models

\begin{tabular}{|c|c|c|c|c|c|c|c|}
\hline Variable & ARIMA & AIC & Adj. $R^{2}$ & SE of $R$ & RMSE & MAE & MAPE \\
\hline \multirow{8}{*}{ 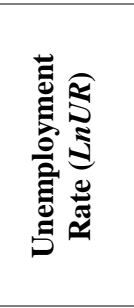 } & $(1,1,1)$ & -1.3346 & 0.0728 & 0.1127 & 0.1170 & 0.0895 & 84.5950 \\
\hline & $(1,1,0)$ & -1.2935 & -0.0615 & 0.1206 & 0.1171 & 0.0899 & 86.2104 \\
\hline & $(2,1,0)$ & -1.2711 & -0.0505 & 0.1200 & 0.1180 & 0.0898 & 84.9073 \\
\hline & $(2,1,1)$ & -1.3871 & 0.1680 & 0.1068 & 0.1183 & 0.0895 & 83.0232 \\
\hline & $(0,1,1)$ & -1.2998 & -0.0544 & 0.1202 & 0.1138 & 0.0856 & 85.7923 \\
\hline & $(0,1,2)$ & -1.2803 & -0.0319 & 0.1189 & 0.1106 & 0.0854 & 121.8211 \\
\hline & $(1,1,2)$ & -1.3531 & 0.1260 & 0.1094 & 0.1171 & 0.0897 & 84.6967 \\
\hline & $(2,1,2)$ & -1.3198 & 0.1355 & 0.1088 & 0.1184 & 0.0897 & 83.4544 \\
\hline \multirow{8}{*}{ 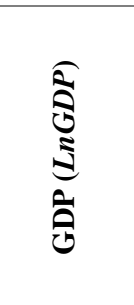 } & $(1,1,0)$ & -0.5873 & -0.0614 & 0.1717 & 0.1664 & 0.1251 & 231.0658 \\
\hline & $(1,1,1)$ & -0.5190 & -0.1031 & 0.1750 & 0.1665 & 0.1251 & 232.3974 \\
\hline & $(2,1,0)$ & -0.5196 & -0.1024 & 0.1750 & 0.1609 & 0.1192 & 214.6644 \\
\hline & $(2,1,1)$ & -0.4507 & -0.1483 & 0.1786 & 0.1609 & 0.1192 & 214.6813 \\
\hline & $(0,1,1)$ & -0.5865 & -0.0624 & 0.1718 & 0.1627 & 0.1221 & 215.9902 \\
\hline & $(0,1,2)$ & -0.5231 & -0.0967 & 0.1745 & 0.1623 & 0.1269 & 224.1541 \\
\hline & $(1,1,2)$ & -0.4564 & -0.1393 & 0.1779 & 0.1667 & 0.1256 & 246.1145 \\
\hline & $(2,1,2)$ & -0.4785 & -0.0184 & 0.1682 & 0.1595 & 0.1179 & 204.9136 \\
\hline
\end{tabular}

The most appropriate ARIMA models for determining the forecasting values of the unemployment rate and GDP series of Turkey in the prediction period are determined by taking the Akaike Information Criterion (AIC) into account. Looking at Table 3, the most appropriate model determined in the unemployment forecasting is ARIMA $(2,1,1)$, which has the lowest AIC value (-1.3871). In order to predict GDP, the most appropriate model determined is ARIMA (1,1,0), which has the lowest AIC value (-0.5873). The most appropriate ARIMA models for unemployment and GDP series are also supported by model measurement criteria like adjusted $R^{2}$ (Adj. $R^{2}$ ) and standard error of regression (SE of R). In addition, when determining forecasting models for the unemployment rate and GDP series, the statistics of RMSE, MAE and MAPE model measurement criteria are also given in Table 3.

After determining the most appropriate ARIMA models in order to obtain the unemployment rate and GDP forecasting values, the models are estimated and the prediction models are presented in numbers 8 and 9. Whether there is an autocorrelation problem between the residual values of the estimated unemployment and GDP ARIMA models has been investigated with the Box-Pierce (BP) and Ljung-Box (LB) tests by choosing the maximum lag length 3 . The tests have been evaluated at the 0.05 significance level. Box-Pierce and Ljung-Box test statistics values for the unemployment rate ARIMA $(2,1,1)$ model's residual series are smaller than the chi-square table value $\left(B P_{\text {stat }}\right.$. value $=0,182$ and $L B_{\text {stat }}$. value $\left.=0,208<x^{2}(3)=7,815\right)$, so the $H_{0}$ hypothesis, which states that there is no significant relationship between the residual series, could not be rejected, and it has been decided that there is no autocorrelation problem between the residual series. Likewise, since the Box-Pierce and Ljung-Box test statistics values for the GDP ARIMA $(1,1,0)$ model's residual values are smaller than the chi-square table value $\left(B P_{\text {stat }}\right.$. value $=2,707$ and $L B_{\text {stat }}$. value $\left.=3,072<x^{2}(3)=7,815\right)$, the $H_{0}$ hypothesis, which states that there is no significant relationship between the residual series, could not be rejected, and it has been decided that there is no autocorrelation problem between the GDP ARIMA $(1,1,0)$ model's residual series.

4- Forecasting:

The most appropriate ARIMA models to be used in order to obtain the forecasting values for the 1988-2017 prediction period have been estimated and the determined models are given below.

$\operatorname{ARIMA}(2,1,1)$ Unemployment Model:

$\Delta L n U R_{t}=0.011189+0.872722 \Delta L n U R_{t-1}-0.336293 \Delta L n U R_{t-2}-u_{t-1}$

$\operatorname{ARIMA}(1,1,0)$ GDP Model:

$\Delta \operatorname{LnGDP_{t}}=0.077220-0.117074 \Delta \operatorname{LnGDP} t-1$

When predictions are made with the ARIMA models given above, the values obtained will not be level values, but will be the forecasting values of difference series. Therefore, in order to find the values of $L n U R_{t}$ and $L n G D P_{t}$, not $\Delta L n U R_{t}$ and $\Delta L n G D P_{t}$, the following unemployment and GDP prediction models can be used.

$$
\begin{aligned}
& \operatorname{LnUR}_{t}-\operatorname{LnUR}_{t-1}=\alpha_{0}+\alpha_{1}\left(\operatorname{LnUR}_{t-1}-\operatorname{LnU} R_{t-2}\right)-\alpha_{2}\left(\operatorname{LnUR_{t-2}}-\operatorname{LnU} R_{t-3}\right)-\alpha_{3}\left(u_{t-1}-u_{t-2}\right) \\
& L n G D P_{t}-\operatorname{LnGDP}_{t-1}=\beta_{0}-\beta_{1}\left(L n G D P_{t-1}-\operatorname{LnGDP_{t-2}}\right)
\end{aligned}
$$


$\alpha_{0}, \alpha_{1}, \alpha_{2}, \alpha_{3}, \beta_{0}$ and $\beta_{1}$ parameters have already been predicted on models 8 and 9 . When the predicted parameters are written in their places on models numbered 10 and 11 ;

$$
\begin{aligned}
& L n U R_{t}-\operatorname{LnUR}_{t-1}=0.011189+0.872722\left(L n U R_{t-1}-\operatorname{LnUR}_{t-2}\right)-0.336293\left(\operatorname{LnU} R_{t-2}-\operatorname{LnU}_{t-3}\right) \\
& -\left(u_{t-1}-u_{t-2}\right)
\end{aligned}
$$

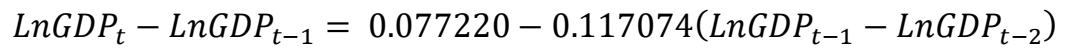

results are obtained.

Unemployment rate and GDP forecasting values for the prediction period have been obtained by writing in their places the level values belonging to the series in models numbered 12 and 13 . The actual values and forecasting values of the series are graphically compared and given in Figure 5 and Figure 6.

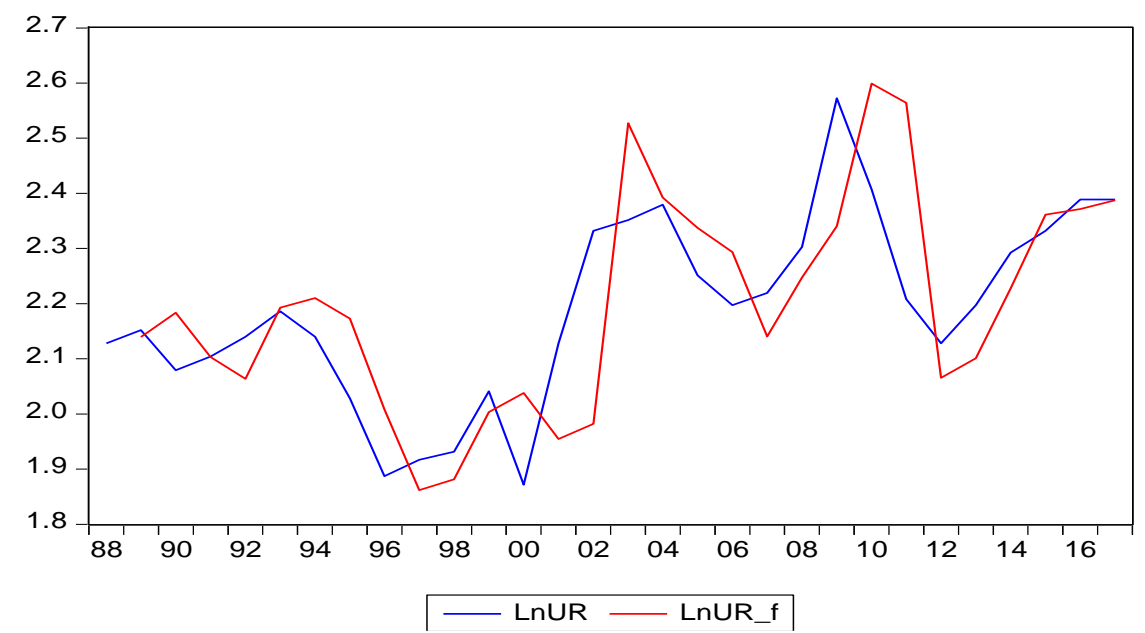

Figure 5. Time series chart belonging to the actual and forecasting values of unemployment in prediction period

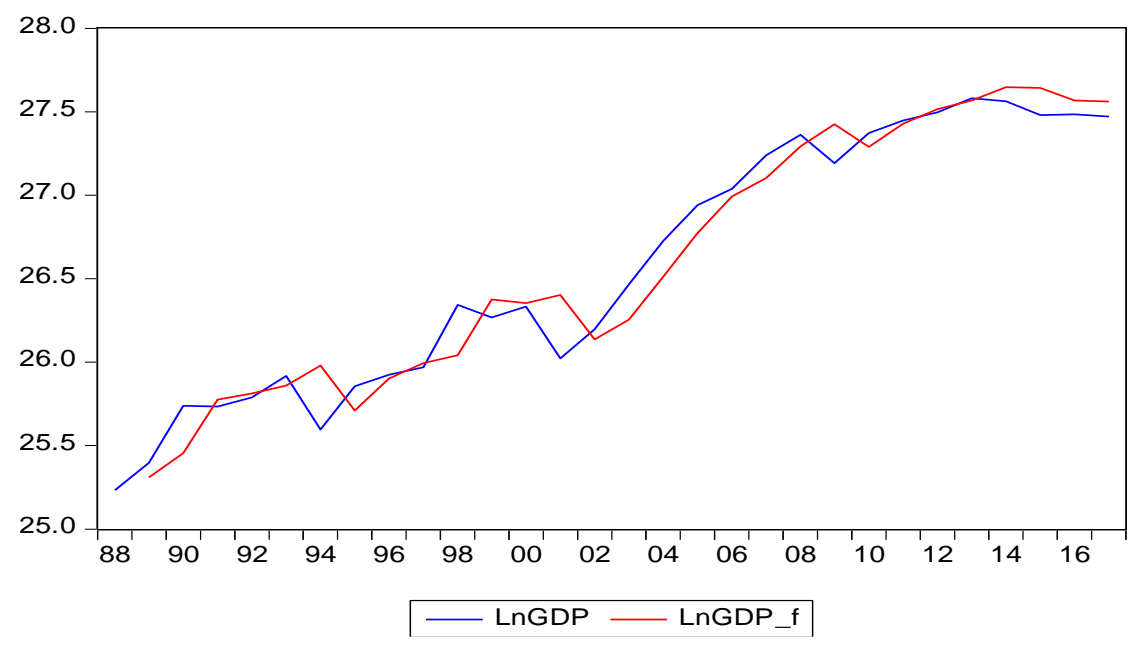

Figure 6. Time series chart belonging to the actual and forecasting values of GDP in prediction period

Looking at Figure 5 and Figure 6, it is observed that the actual and forecasting values of unemployment rate and GDP are close to each other during the prediction period and that they show similar fluctuations over time. In this case, it can be said that ARIMA $(2,1,1)$ and $\operatorname{ARIMA}(1,1,0)$ models are successful in forecasting unemployment and GDP series respectively, and forecasting process for the ex-post period can be started. The forecasting values and actual values determined for the period 2018-2019 are given in Table 4.

According to Table 4, the error rate between the forecasting value and actual value of unemployment variable in 2018 is lower than in 2019. Absolute percent error values between the actual values and forecasting values of the GDP variable in the ex-post period are at a level that can be considered quite well. In the ex-post forecasting period, it is seen that the forecasting sensitivity of GDP prediction model ARIMA $(1,1,0)$ is better than unemployment prediction model ARIMA $(2,1,1)$. 
Table 4. Comparison of forecasting values and actual values of unemployment rate and GDP in ex-post forecasting period

\begin{tabular}{|c|c|c|c|c|c|c|}
\hline \multirow[b]{2}{*}{ Year } & \multicolumn{3}{|c|}{ Unemployment Rate $(\operatorname{LnUR})$} & \multicolumn{3}{|c|}{ GDP $(\operatorname{LnGDP})$} \\
\hline & Actual Value & $\begin{array}{l}\text { Forecasting } \\
\text { Value }\end{array}$ & $\begin{array}{c}\text { Absolute Percent } \\
\text { Error }\end{array}$ & Actual Value & $\begin{array}{c}\text { Forecasting } \\
\text { Value }\end{array}$ & $\begin{array}{c}\text { Absolute Percent } \\
\text { Error }\end{array}$ \\
\hline 2018 & 2.398 & 2.423 & 1.036 & 27.371 & 27.550 & 0.654 \\
\hline 2019 & 2.617 & 2.396 & 8.462 & 27.349 & 27.460 & 0.406 \\
\hline
\end{tabular}

Forecasting values obtained during the prediction period and ex-post period have given significant statistical results and are an important step in obtaining the forecasting values designed for the ex-ante period. Forecasting results for the ex-ante period are presented in Table 5.

Table 5. Forecasting results for the ex-ante period

\begin{tabular}{rrrrr}
\hline Year & LnUR & UR & LnGDP & GDP (Million \$) \\
\hline $\mathbf{2 0 2 0}$ & 2.634 & 13.93 & 27.429 & 817.078 \\
\hline $\mathbf{2 0 2 1}$ & 2.772 & 15.99 & 27.497 & 874.572 \\
\hline $\mathbf{2 0 2 2}$ & 2.743 & 15.53 & 27.566 & 937.048 \\
\hline $\mathbf{2 0 2 3}$ & 2.861 & 17.48 & 27.635 & 1.003 .987 \\
\hline $\mathbf{2 0 2 4}$ & 2.825 & 16.86 & 27.704 & 1.075 .708 \\
\hline $\mathbf{2 0 2 5}$ & 2.923 & 18.60 & 27.774 & 1.153 .705 \\
\hline
\end{tabular}

In light of the information in Table 5, it is clear that the unemployment series increases in a fluctuating manner during the ex-ante period, and the GDP series tends to increase constantly over the years.

\section{Conclusion and Evaluation}

AR, MA and ARIMA models have generally been used as unemployment and economic growth forecasting models in the literature. In this study, ARIMA is the preferred forecasting model because the actual values of the prediction period are not stationary series at the level I(0). By applying the Box-Jenkins methodology, the most appropriate ARIMA models have been built up to obtain forecasting values. In this context, ARIMA $(2,1,1)$ models for unemployment rate forecasting and ARIMA $(1,1,0)$ models for GDP forecasting have been determined as the most appropriate models. First of all, forecasting values for the prediction period (1988-2017) have been found and then compared with the actual values. Actual and forecasting values of unemployment and GDP in the prediction period have been graphically given and it has been observed that actual and forecasting values of both series exhibit similar fluctuations and breakdowns. Secondly, for the ex-post period (2018-2019), forecasting values of unemployment rate and GDP have been obtained, and it has been observed that there is no significant difference between actual values and forecasting values. It has been determined by using the absolute percentage error criterion that forecasting sensitivity is at the desired acceptable level. Finally, forecasting values for the ex-ante period (20202025) have been designed by using the most appropriate ARIMA forecasting models. It has been determined that unemployment forecasting values will increase fluctuately over the years during the ex-ante period. In the ex-ante period, GDP forecasting values tend to increase constantly, and they provide an insight into the sustainability of economic growth.

It has been observed that the unemployment and economic growth predictions for Turkey obtained from the econometric forecasting study offer similar statistical results as studies conducted in previous years. Unemployment rates have been predicted to be on a rising trend in the coming years, as in previous studies. It has been concluded that economic growth policies in Turkey will continue in the following years, but high economic growth is not reflected in unemployment rates and therefore unemployment will not decrease, but will continue in double digits.

The fluctuating increase of unemployment rates in Turkey in the coming years can be explained by the following statements: Assuming that the fluctuating increase in exchange rates happening in recent years, that is, the loss of power of the Turkish Lira against foreign currencies (dollars, euros) may continue, a significant increase in the prices of the imported raw materials used in the production line will leave the industry in Turkey in a difficult situation at the point of increasing their costs. In this case, the industry will strive to produce at the same rate by employing less workers in order to minimize the cost they bear for raw materials which they use in production line. The empirical analysis has indicated that there will be an increase in the layoff rates. In parallel with the constant increase in Turkey's unemployment rates in the coming years, the rising trend of economic growth indicates that the need for the manpower in the production line will decrease, but the quality and high rate of production can be achieved with the widespread use of developing and changing technological innovations in production line. 
Forecasting economic growth and unemployment variables for Turkey with the help of the most appropriate ARIMA models is a reference for the economic growth and unemployment prediction studies to be carried out in the world in the following years. In the study, both the theoretical and practical dimensions of the ARIMA model have been discussed in detail and the success of forecasting has been evaluated. It is important for future studies to examine economic growth and unemployment variables for national economies with different forecasting models and to compare the results with the predictions made with ARIMA models.

\section{References}

[1] B. Ali, T. Altintas, Time Series Analysis: A Case Study on Forecasting Turkey's Inflation and Unemployment, Journal of ABMYO, 39 (2015), 65-75.

[2] B. Meyer, M. Tasci, Lessons for Forecasting Unemployment in the United States: Use Flow Rates, Mind the Trend, Federal Reserve Bank of Atlanta Working Paper Series, No:2015-1 (2015)

[3] M. Tasci, C. Treanor, Forecasting Unemployment in Real Time during the Great Recession: An Elusive Task, Federal Reserve Bank of Cleveland Economic Commentary, No:2015-15 (2015)

[4] S. Karlsson, F. Javed, Modeling and Forecasting Unemployment Rate In Sweden Using Various Econometric Measures (Masters in Applied Statistics), Örebro: Örebro University School of Business (2016)

[5] U. Mahmudah, Predicting Unemployment Rates in Indonesia, Economic Journal of Emerging Markets, 9(1) (2017), $20-28$.

[6] A. Tuzemen, C. Yildiz, Holt-Winters Forecast Methods' Comparative Analysis: Turkey Unemployment Rates Implementation, Ataturk University Journal of Economics and Administrative Sciences, 32(1) (2018), 1-18.

[7] N. Dritsakis, P. Klazoglou, Forecasting Unemployment Rates in USA Using Box-Jenkins Methodology, International Journal of Economics and Financial Issues, 8(1) (2018), 9-20.

[8] O. Claveria, Forecasting the Unemployment Rate Using the Degree of Agreement in Consumer Unemployment Expectations, Journal for Labour Market Research, 53(3) (2019), 1-10.

[9] T. Wang, Forecast of Economic Growth by Time Series and Scenario Planning Method-A Case Study of Shenzhen, Modern Economy, 7 (2016), 212-222.

[10] P. Higgins, T. Zha, K. Zhong, Forecasting China's Economic Growth and Inflation, Nber Working Paper Series, National Bureau of Economic Research, No. 22402 (2016), 1-23.

[11] C. Chuku, A. Simpasa, J. Oduor, Intelligent Forecasting of Economic Growth for Developing Economies, International Economics, 159 (2019), 74-93.

[12] H. Erdogdu, Forecasting Turkey’s GDP Growth with Mixed Data Sampling (MIDAS) Method, Iğdır University Journal of Social Sciences, 22 (2020), 519-541.

[13] G. Gecgil, Y. Akgul, A Study on the Prediction of Neural Network Value of Turkey’s GDP, Journal of Quantitative Sciences, 2(1) (2020), 61-77.

[14] S.V. Jeric, D. Zoricic, D. Dolinar, Analysis of Forecasts of GDP Growth and Inflation for the Croatian Economy, Economic ResearchEkonomska Istrazivanja, 33 (2020), 310-330.

[15] Turkey Statistical Institute, Basic Statistics, https://tuikweb.tuik.gov.tr/UstMenu.do?metod=temelist, (Accessed in December 2020).

[16] World Bank, DataBank, World Development Indicators, https://databank.worldbank.org/source/world-development-indicators, (Accessed in December 2020).

[17] R. Tari, Econometrics. Extended 13th Edition, Kocaeli: Umuttepe Publications (2018).

[18] D. N. Gujarati, D. C. Porter, Basic Econometrics. Translations U. Senesen and G. G. Senesen. 5th Edition, İstanbul: Literature Publications (2018).

[19] A. Kutlar, Applied Econometrics. Improved 3th Edition, Ankara: Nobel Publication Distribution (2009). 